\title{
仮想歩行モデルを用いた二次元平面上での人型ロボットの歩行生成
}

\section{Simple Virtual Biped Model Based Walking Pattern Generator for a Planar Humanoid Robot}

\author{
$\bigcirc$ 原田譫 (武蔵工大) 学 宮原謙太郎 (武蔵工大) \\ 正金宮好和 (武蔵工大) 正佐藤 大祐 (武蔵工大)
}
Yuzuru HARADA, Musashi Institute of Technology, harada@rls.mes.musashi-tech.ac.jp Kentaro MIYAHARA, Musashi Institute of Technology Yoshikazu KANAMIYA (D. N. Nenchev), Musashi Institute of Technology Daisuke SATO, Musashi Institute of Technology

The aim of our research is walking pattern generation for a humanoid robot based on the Passive Dynamic Walk (PDW) concept. The stability of the walking pattern is of main concern. It is well known that stable walk is possible, provided the system parameters and the initial conditions are chosen carefully. So far, no explicit relation between initial conditions and stability are known. Therefore, the conditions are usually set empirically. But this is feasible only for simple models. In this work, we show how a stable walking pattern for a multilink (four-link) planar model can be generated via a simple two-link PDW model. The walking pattern is then realized via the computed torque method. Results are demonstrated based on data from simulations.

Key Words: Passive Dynamic Walk, Biped Walking, Virtual Model

\section{1 緒言}

現在，様々な研究者によって受動歩行に基づいた制御法 が研究されている。受動歩行は斜面を下ることにより位置 エネルギーを運動エネルギーに変換して継続した歩行を 行っている. 浅野らは,このエネルギ一回復メカニズムに 着目し，受動歩行の特性を残したまま平地での歩行を可能 とした仮想受動歩行を提案した $[1]$. しかし，受動歩行に 基づいた制御法は，目標軌道に対するフィードバック制御 要素を含まず, 歩行の安定性はモデルの物理パラメータと 初期状態によって決定される。解析的手法を用いた安定性 解析の研究も続けられているが, その非線形システムの複 雑さから, 構造解析は難航している [2][3]. そのため現状 では，数値的な手法を用いて安定サイクルを探索する必要 がある，人型ロボットへの適用を考えたとき，歩行モデル の複雑化は必須であるが, 自由度の増加は安定サイクルの 数值的探索を困難なものとする。そこで本稿では，安定サ イクルの探索が比較的容易な 2 自由度歩行モデルを仮想歩 行モデルとし，その歩行パターンを利用して，複雑な歩行 モデルの歩行パターンを生成する手法を提案する。まず, 仮想歩行モデルを用いた歩行パ夕ーン生成の手順を説明す る，次に，仮想歩行モデルを用いて，遊脚に膝関節と足首 関節をもった歩行モデルの歩行シミュレーションを行い, 安定歩行パターンの生成が可能であることを示す。

\section{2 歩行モデルの設定}

本稿では Fig. 1 に示すような平面 2 足ロボットモデル を用いる。ただし，支持脚の足部は片足支持期においては 地面に固定されているものとし，4自由度のモデルとして 扱う。このモデルの片脚支持期の運動は, 以下に示した運

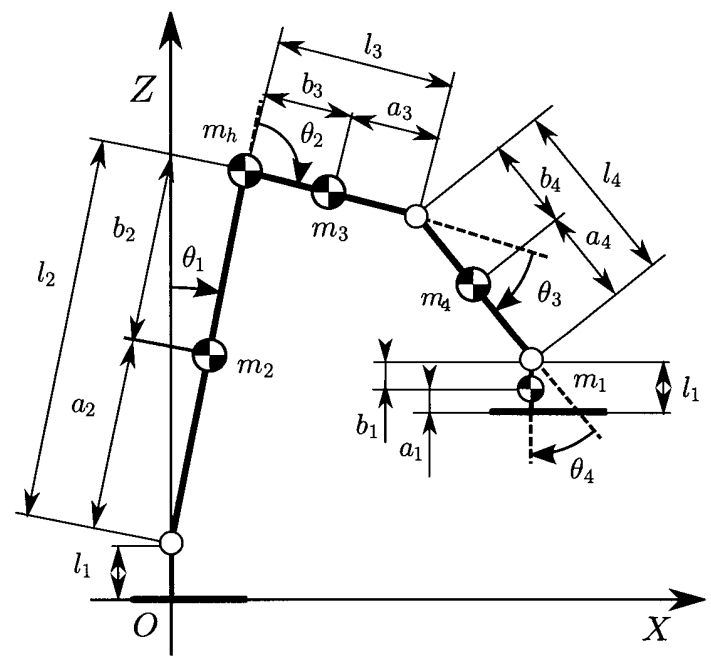

Fig. 1: Four-link biped model.

動方程式で与えられる.

$$
M(\theta) \ddot{\theta}+C(\theta, \dot{\theta}) \dot{\theta}+\boldsymbol{g}(\boldsymbol{\theta})=\boldsymbol{\tau}
$$

ただし， $\boldsymbol{\theta}=\left[\begin{array}{llll}\theta_{1} & \theta_{2} & \theta_{3} & \theta_{4}\end{array}\right]^{T}$ は，一般化座標ベクトル

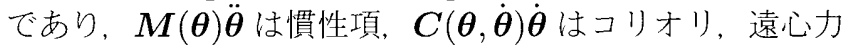
項, $\boldsymbol{g}(\boldsymbol{\theta})$ は重力項, $\boldsymbol{\tau}$ は各関節に与えるトルクとする.

またこのモデルは歩行運動中に遊脚先端と床の衝突を 含む. 本稿では、この衝突を完全非弾性衝突と仮定する.

\section{3 仮想歩行モデルの導入}

受動歩行に基づいた歩行パターンにおいて，安定歩行サ イクルを数值的な手法で探索するのは歩行モデルが複雑に なるほど困難になる，本稿ではその対策として，簡単な仮 想歩行モデルの歩行サイクルを基礎に, より複雑なモデル 
での歩行パターンの生成を行った，歩行パターン生成の手 順は以下の通りである。

1. Fig. 2 に示した仮想歩行モデルを用いて仮想受動歩行 のシミュレーションを行った。

2. シミュレーション結果より, Fig. 1 のモデルの支持脚 足首拧よび股関節の目標值 $\theta_{1 d}, \theta_{2 d}, \dot{\theta}_{1 d}, \dot{\theta}_{2 d}, \ddot{\theta}_{1 d}$, $\ddot{\theta}_{2 d}$ を得た。

3. 仮想歩行モデルに対応するものが存在しない遊脚膝お よび足首関節の目標軌道 $\theta_{3 d}, \theta_{4 d}, \dot{\theta}_{3 d}, \dot{\theta}_{4 d}, \ddot{\theta}_{3 d}, \ddot{\theta}_{4 d}$ を設定した。

4. 歩行モデルを計算トルク法を用いて, 上記の手順で得 た目標軌道に追従させ，歩行パターンを生成した。

以下にこの過程の詳細を示す.

\section{1 仮想歩行モデル}

本稿では Fig. 2 のような 2 自由度の平面 2 足歩行ロボッ トを仮想歩行モデルとして用いた。

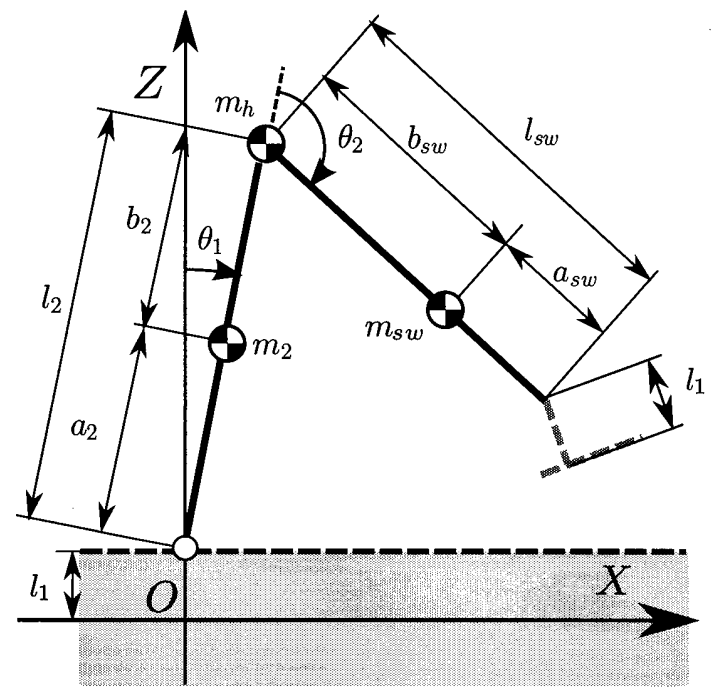

Fig. 2: Virtual biped model for generating the target trajectory.

これは，2 自由度歩行モデルの安定サイクルの探索が最 も容易であるためである。仮想歩行モデルの自由度は受動 歩行分野において一般的に用いられているコンパス型モデ ルと等しい，しかし，歩行モデルの歩行パターン生成に用 いるため，仮想歩行モデルの設定は遊脚と床の衝突の際に 生じる Fig. 1 との差異を考慮して行う必要がある。これ は，片脚支持期の運動とは異なり，衝突による状態变化を 制御することが不可能であるためである。 そこで，本稿で は，床との衝突時の仮想歩行モデルの状態が歩行モデルの ものと近くなるように以下の設定を施した。

$$
\begin{gathered}
m_{s w}=m_{1}+m_{3}+m_{4} \\
l_{s w}=l_{3}+l_{4} \\
a_{s w}=l_{s w}-b_{s w} \\
b_{s w}=\frac{m_{1}\left(l_{3}+l_{4}+b_{1}\right)+m_{4}\left(l_{3}+b_{4}\right)+m_{3} b_{3}}{m_{s w}}
\end{gathered}
$$

設定 1 遊脚質量 $m_{s w}$ を式 $(2)$ のように設定した.

設定 2 遊脚リンク $l_{s w}$ の長さを式 $(3)$ のように設定した.

設定 3 遊脚先端に， $l_{1}$ と同じ長さの, 質量を持たない足 部リンクを追加した。

設定 4 遊脚の重心位置 $a_{s w}, b_{s w}$ を式 (4), (5) のように 設定した。

設定 1 は仮想歩行モデルの遊脚質量を歩行モデルと等し くするための設定である。また，衝突時の仮想歩行モデル の角運動量が歩行モデルのものに近付くようにするために は，質量だけでなく，衝突時の遊脚質点の位置べクトルを 調整する必要がある。設定 $2 ， 3 ， 4$ はそのための設定で ある、設定 4 は遊脚の重心位置の設定を行っている. 衝 突直前の仮想歩行モデルの状態を歩行モデルと一致させる には，遊脚の重心位置を Fig. 3 の (A) のように接地時の 遊脚の状態から設定するのが最善と考えられる。しかし， このように設定した場合，足部リンクの重心位置が，衝突 時の姿勢によって変化する．仮想歩行モデルの安定サイク ル探索には数值的な手法を用いる必要があるため, 歩行パ ターンによってモデルのマスプロパティが変化するの重大 な問題となる、そのため, 本稿では次善策として遊脚の重 心位置を Fig. 3 の (B) のように設定した。この設定の場 合，歩幅が大きくなるにつれて衝突時の状態の差異が大き くなるという問題があるが，予め重心位置が固定されてい るため, 安定サイクルの数值的探索の障害にはならない.

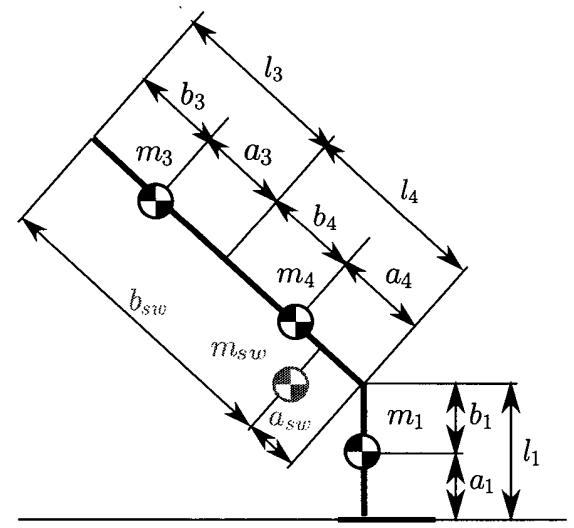

(A) Ideal setting

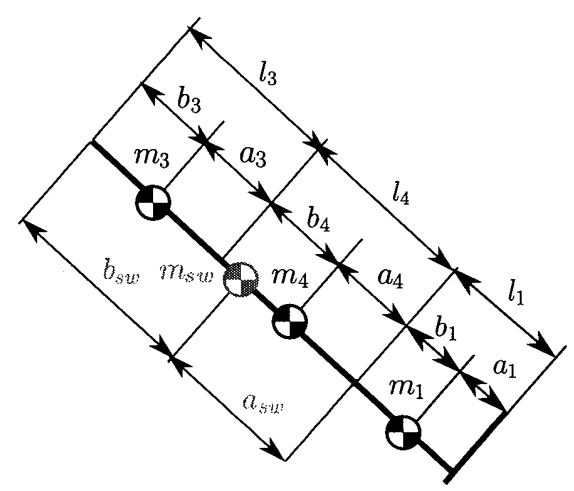

(B) Setting in this paper

Fig. 3: Setting of swing leg mass of the virtual biped model. 


\section{2 追加関節の目標軌道}

Fig. 2 の仮想歩行モデルには遊脚膝および足首関節が存 在しない，そのため、Fig. 1 の歩行モデルの歩行パターン を生成するためには，遊脚膝および足首関節の目標軌道を 別に設定する必要がある。まず，膝関節の目標軌道は膝関 節のスムーズな動作を考慮し，遊脚膝関節の目標軌道 $\theta_{3 d}$, $\dot{\theta}_{3 d}, \ddot{\theta}_{3 d}$ を以下に示した時間関数を用いて設定した。この ように目標値を設定することで，㮏関節の衝突によるエネ ルギー損失を回避することが可能となる [1].

$$
\theta_{3 d}= \begin{cases}A \sin ^{3}\left(\frac{\pi}{T} t\right) & (t \leq T) \\ 0 & (t>T)\end{cases}
$$

ただし， $T$ は目標整定時間であり，遊脚接地時間以前に存 在することとする，この仮定より，歩行モデルは膝関節を 伸ばしきった状態で床との衝突を行うことになる，次に遊 脚足首関節の目標軌道 $\theta_{4 d}, \dot{\theta}_{4 d}, \ddot{\theta}_{4 d}$ は接地を考慮し, 歩 行モデルの足裏が常に地面と平行になるように設定した。

\section{3 制御入力}

式 (1) のトルク $\tau$ を次式のように設定した。本稿 では，制御に計算トルク法を用いた [4]。これにより， 系を関節变位に対して線形化した上で，仮想歩行壬 デルより得られた目標值および任意に設定した遊脚 の膝関節，足首関節の目標值に対して PD 制御を行 った。ただし， $\boldsymbol{K}_{p}=\operatorname{diag}\left[\begin{array}{llll}K_{p 1} & K_{p 2} & K_{p 3} & K_{p 4}\end{array}\right]$, $\boldsymbol{K}_{d}=\operatorname{diag}\left[\begin{array}{llll}K_{d 1} & K_{d 2} & K_{d 3} & K_{d 4}\end{array}\right]$ とする.

$$
\begin{aligned}
\boldsymbol{\tau} & =\boldsymbol{M}(\boldsymbol{\theta}) \boldsymbol{u}+\boldsymbol{C}(\boldsymbol{\theta}, \dot{\boldsymbol{\theta}}) \dot{\boldsymbol{\theta}}+\boldsymbol{g}(\boldsymbol{\theta}) \\
\boldsymbol{u} & =\ddot{\boldsymbol{\theta}}_{d}+\boldsymbol{K}_{p}\left(\boldsymbol{\theta}_{d}-\boldsymbol{\theta}\right)+\boldsymbol{K}_{d}\left(\dot{\boldsymbol{\theta}}_{d}-\dot{\boldsymbol{\theta}}\right)
\end{aligned}
$$

\section{4 数値シミュレーション}

本稿でシミュレーションに用いた歩行モデルの物理パ ラメータを Table 1 に示した. ただし， $m_{t}$ は歩行モデル の合計質量である。また，仮想歩行モデルのシミュレー ションに用いる仮想斜面角度を $\phi=0.02 \mathrm{rad}, \mathrm{PD}$ 制 御のゲインを $\boldsymbol{K}_{p}=\operatorname{diag}\left[\begin{array}{llll}300 & 300 & 400 & 100\end{array}\right] \mathrm{s}^{-2}$, $\boldsymbol{K}_{d}=\operatorname{diag}\left[\begin{array}{llll}30 & 30 & 50 & 50\end{array}\right] \mathrm{s}^{-1}$, 膝関節の目標整定時 間を $T=0.56 \mathrm{~s}$ として $4 \mathrm{~s}$ のシミュレーションを行った.

Table 1: Parameters of the four-link biped model

\begin{tabular}{|c|c|c||c|c|c|}
\hline$m_{1}$ & {$[\mathrm{~kg}]$} & 1.0 & $l_{2}$ & {$[\mathrm{~m}]$} & 1.0 \\
\hline$m_{2}$ & {$[\mathrm{~kg}]$} & 5.0 & $l_{3}$ & {$[\mathrm{~m}]$} & 0.5 \\
\hline$m_{3}$ & {$[\mathrm{~kg}]$} & 2.5 & $l_{4}$ & {$[\mathrm{~m}]$} & 0.5 \\
\hline$m_{4}$ & {$[\mathrm{~kg}]$} & 2.5 & $a_{1}, b_{1}$ & {$[\mathrm{~m}]$} & 0.125 \\
\hline$m_{h}$ & {$[\mathrm{~kg}]$} & 10.0 & $a_{2}, b_{2}$ & {$[\mathrm{~m}]$} & 0.5 \\
\hline$m_{t}$ & {$[\mathrm{~kg}]$} & 21.0 & $a_{3}, b_{3}$ & {$[\mathrm{~m}]$} & 0.25 \\
\hline$l_{1}$ & {$[\mathrm{~m}]$} & 0.25 & $a_{4}, b_{4}$ & {$[\mathrm{~m}]$} & 0.25 \\
\hline
\end{tabular}

Fig.4にシミュレーション結果を示した。各グラフは (a) 各関節の角度, (b) 各関節の角速度, (c) 力学的エネルギー, (d) 関節角度のエラ一, (e) 関節角速度のエラー, (f) 入力 トルクを示している。 また, Fig. 5 に生成された歩行の様 子の一部を示した。

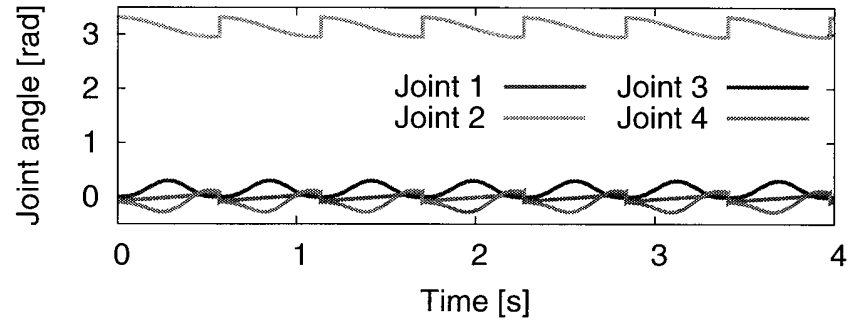

(a)

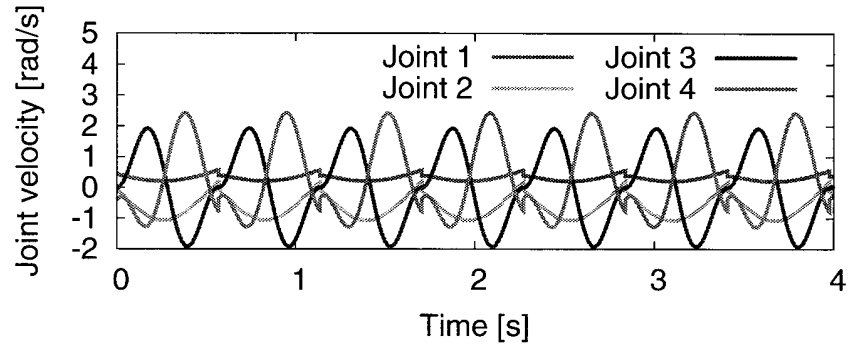

(b)

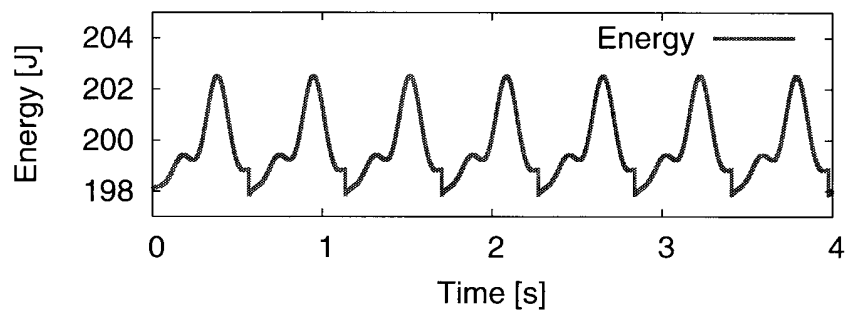

(c)

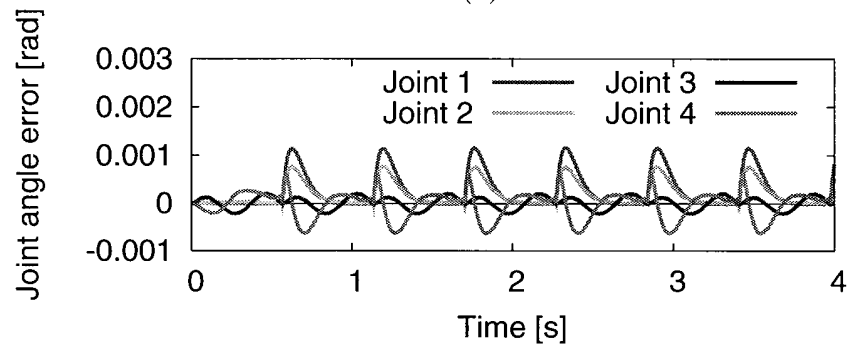

(d)

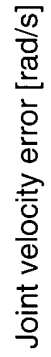

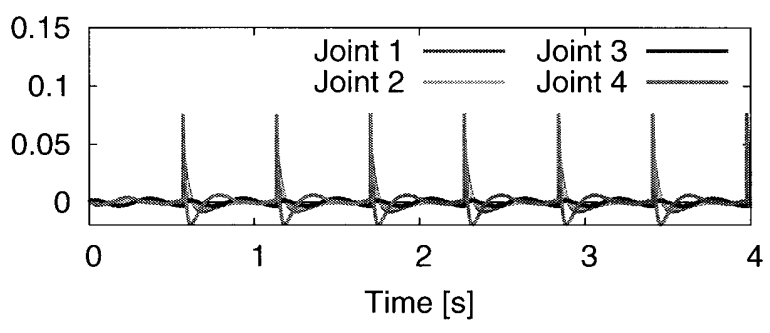

(e)

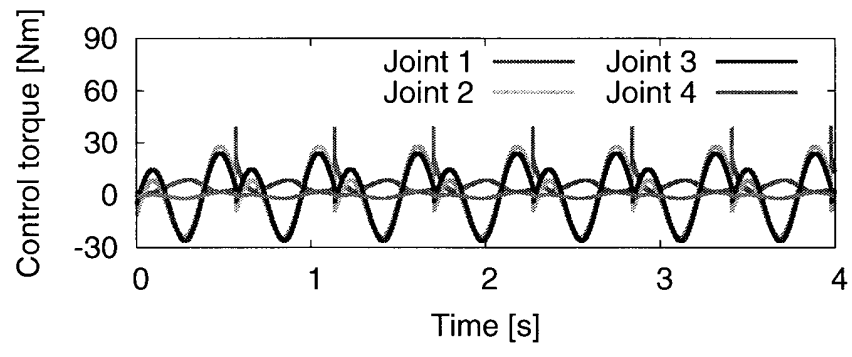

(f)

Fig. 4: Simulation results of four-link biped model. 


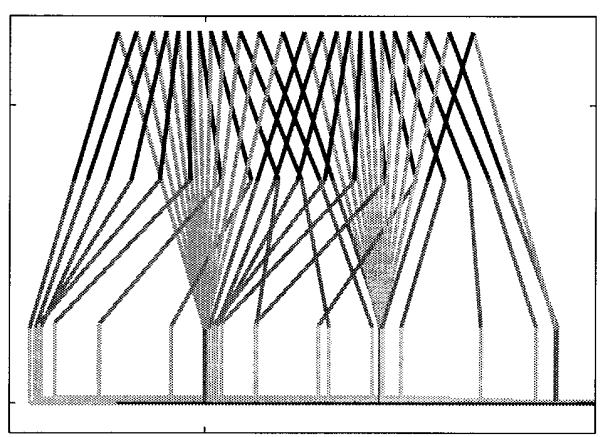

Fig. 5: Walking pattern of four-link biped model based on virtual biped model.

Fig. 4 の (a), (b) から, 各関節の角度, 角速度の時間変 化が每歩行周期で同様のものになっていることが分かる. また, (c) から, 力学的エネルギーの平衡状態が分かる. このことから，仮想歩行モデルを用いて生成された歩行パ ターンが定常的な歩行サイクルとなっていることが確認で きる，(d)，(e)を見ると，遊脚と床の衝突時にエラーが一 時的に増大している。 このエラーにより, 衝突直後の入力 トルクが瞬間的に大きくなっていることが (f) から分かる. これは, 衝突時の仮想歩行モデルの状態が, 歩行モデルと 完全に一致していないことが原因である。しかし、計算卜 ルク法による制御によって, 衝突後速やかに目標値に追従 し，エラーが減少していることも確認できる.

\section{4 結言と今後の課題}

本稿では，仮想歩行モデルを用いた歩行パターンの生成 法を提案した。 また, 数值シミュレーションによって，4 リンクモデルの安定した歩行パターンの生成が可能である ことを確認した。

今回は，安定サイクルの探索が容易であるという理由か ら，2自由度のコンパス型モデルを仮想歩行モデルとして 用いた。 そのため，遊脚㮏関節と足首関節の目標軌道は別 に設定した。しかし，今回設定した目標軌道は，歩行運動 に支障をきたさないように留意しただけで，エネルギー効 率の観点から最適化された軌道ではない，そこで，これら の目標軌道をより動力学特性を活かしたものに変更守る必 要がある，特に，影響が大きいと考えられる滕関節の軌道 に関しては，仮想歩行モデル側で生成することも考える. また, 衝突直後に生じるエラーを減少させるため, 仮想歩 行モデルの設定を見直す必要がある。

\section{文 献}

[1] 浅野文彦、羅志偉，山北昌毅，“受動少行を規範とした 2 足ロボットの少行パターン生成と制御”, 日本ロボット学 会誌, vol. 22, no. 1, pp. 130-139, 2004.

[2] 浅野文彦, 羅志偉, “力学的エネルギー平衡に基づく漸近 努定少容生成”, 日本機械学会ロボティクス・メカ卜ロニ

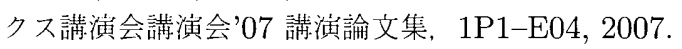

[3] 池俣吉人, 恢野明人, 藤本英雄, “受動少行における平衡点 の安定メカニズムの楧造”、日本ロボット学会誌, vol. 23, no. 7 , pp. 839-846, 2005.

[4] J. J. Craig (三浦宏文, 下山勲 訳)，“ロボティクスー機满・ 力学・制御 -”, 共光出版株式会社, 1991, pp. 260-261.

[No. 08-4] Proceedings of the 2008 JSME Conference on Robotics and Mechatronics, Nagano, Japan, June 5-7, 2008 